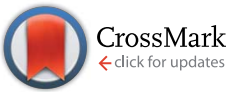

Cite this: RSC Adv., 2016, 6, 115367

DOI: 10.1039/c6ra90135b

www.rsc.org/advances

\section{Correction: Co-Delivery of angiostatin and curcumin by a biodegradable polymersome for antiangiogenic therapy}

Yue Cao, ${ }^{a}$ Yan Li, ${ }^{c}$ Yin Wu, ${ }^{c}$ Wenliang Li, ${ }^{c}$ Chunlei $\mathrm{Yu}^{\mathrm{c}}{ }^{\mathrm{c}}$ Yanxin Huang, ${ }^{\mathrm{b}}$ Luguo Sun, ${ }^{\text {b }}$ Yongli Bao*c and Yuxin $\mathrm{Li}^{\star a}$

Correction for 'Co-Delivery of angiostatin and curcumin by a biodegradable polymersome for antiangiogenic therapy' by Yue Cao et al., RSC Adv., 2016, 6, 105442-105448.

In the original article, parts $\mathrm{C}$ and $\mathrm{D}$ of Fig. 1 were displayed incorrectly and did not match with the text in the figure caption. To clarify this error, the authors have provided an amended Fig. 1 herein which contains corrected versions of parts C and D.
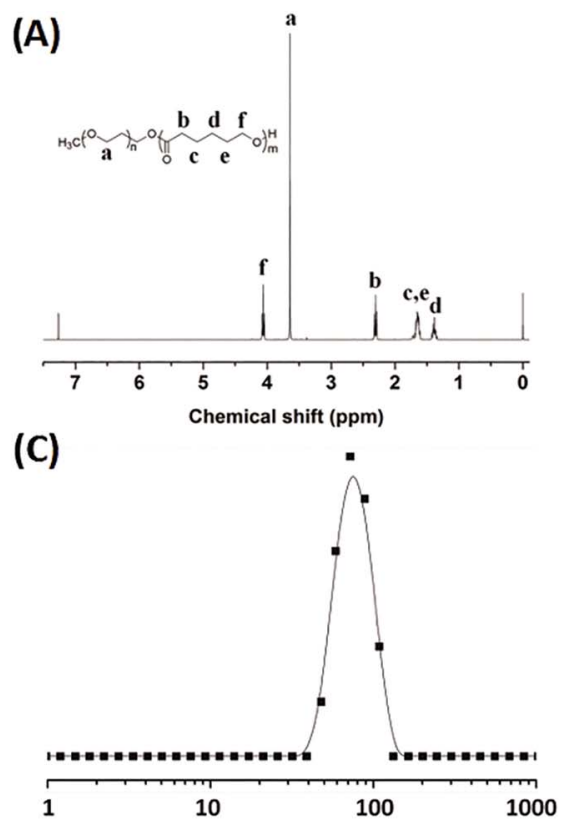

(B)

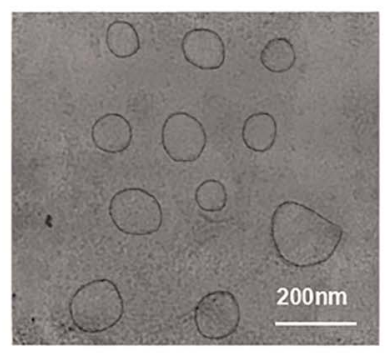

(D)

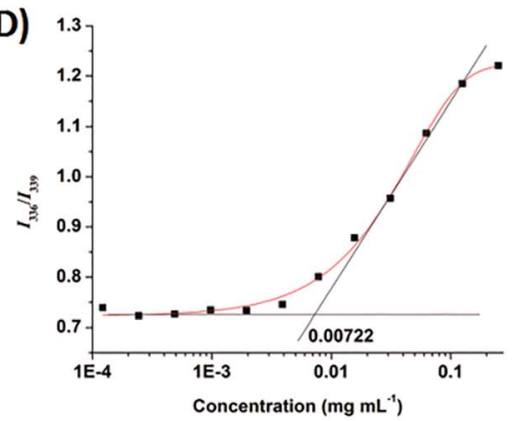

Fig. 1 (A) ${ }^{1} \mathrm{H}$ NMR spectrum (400 MHz, $C D C_{3}$ ) of $\mathrm{mPEG}_{5 \mathrm{k}}-\mathrm{PCL}_{12 \mathrm{k}}$; the blank polymersomes were examined using (B) TEM and (C) DLS; (D) the CAC of the polymersomes.

The Royal Society of Chemistry apologises for these errors and any consequent inconvenience to authors and readers.

${ }^{a}$ National Engineering Laboratory for Druggable Gene and Protein Screening, Northeast Normal University, Jingyue Street 2555, Changchun 130117, P. R. China. E-mail: liyx486@nenu.edu.cn; Fax: +86-431-89165917; Tel: +86-431-89165917

${ }^{b}$ Institute of Genetics and Cytology, Northeast Normal University, Renmin Street 5268, Changchun 130024, P. R. China. E-mail: sunlg388@nenu.edu.cn; Fax: +86-431-89165922; Tel: +86-431-89165922

'School of Life Sciences, Northeast Normal University, Renmin Street 5268, Changchun 130024, P. R. China. E-mail: baoyl800@nenu.edu.cn; Fax: +86-431-89165920; Tel: +86431-89165920 